\title{
FACE SKIN COLOR BASED RECOGNITION USING LOCAL SPECTRAL AND GRAY SCALE FEATURES
}

\author{
T.Anil Raju1, B.Ajanta Reddy ${ }^{2}$, N. Adinarayana ${ }^{3}$ \\ ${ }^{1}$ Asosciate professer, Lakireddy Bali Reddy college of Engineering, Mylavaram-521230, Krishna (Dt) \\ ${ }^{2}$ Student of M.Tech, Lakireddy Bali Reddy college of Engineering, Mylavaram-521230, Krishna (Dt) \\ ${ }^{3}$ Student of M.Tech, Lakireddy Bali Reddy college of Engineering, Mylavaram-521230, Krishna (Dt)
}

\begin{abstract}
Human face conveys more information about identity of person. Human face recognition is one of the most challenging problem and it can be used in many applications at different security places in airports, defense and banking sectors etc.In this work used colored features obtained from color segmentation because in real time scenario color provides the more information than gray scale image but it has a drawback. To overcome this drawback gray scale feature extracted from co-occurrence matrix of an image and for efficient face recognition of human Face under different illumination conditions spectral features can be extracted from face texture. These three feature vectors concatenated into a single feature vector and applied Lenc-Kral matching technique to measure similarity between the database and query image, the similarity is high then face is recognized.
\end{abstract}

Keywords: Face recognition, illumination condition, local texture features, color segmentation. -***

\section{INTRODUCTION}

Face recognition has more robust technology compare to other biometrics [1] because advantage of face recognition is it does not need any physical interaction between person and device. The main idea of face recognition is human face, because it conveys more information and might be unique features like texture, eyes, nose and mouth etc. among these, texture features are more important [2] the basic idea about texture features is face. It has a lot of applications like Airport, defense, banking sectors and many historical places etc.

The human face of a different skin colored people have different skin color due to ultraviolet radiation penetration because skin is more exposure to the UV radiation levels [3]. Skin reflectance is strongly correlated with absolute latitude and UV radiation levels and texture and shape based on their surroundings.

Different approaches has been proposed for face recognition, including Principal component analysis, [4] Linear discriminant analysis [5], independent component analysis [6], kernel methods, neural networks, elastic bunch graph method and wavelets etc.most of the methods were developed on well-controlled environments like uniform background and well aligned faces, but it is impossible in uncontrolled environment [7] to recognize face due to illumination, facial expressions and aging etc.

To overcome these problems in this proposed work consists of three categories for efficient face recognition under different lighting conditions, those are 1.color segmentation 2.Extraction of feature vectors 3.vector comparision.In color segmentation $\mathrm{YCbCr}$ color space model was used for extracted the colored features from skin colored human faces . In Extraction of feature vectors, extracted the two types of features those are local texture features and gay level features. Local texture features are extracted from face texture because face has a composition of micro patterns is called as texture pattern. The main purpose of these features is to recognizing the human face under different lighting conditions. Gray level features extracted from co-occurrence matrix of image for efficient face recognition. In vector comparison, combined these features into a single vector and applied Lenc-kral matching technique. In this technique feature vectors of database and query image compared and measure similarity between these images, similarity is high then face is recognized.

\section{COLOR SEGMENTATION}

Color provides much information about the image than that of gray image.Numorous methods proposed for color segmentation like, RGB, normalized RGB, CMY, CMYK, but these are not well suited for describing colors in variant illumination environment, so we adopt $\mathrm{YCbCr}$ color space. In $\mathrm{YCbCr}$ by decoupling the color information into intensity and chromatic components, $\mathrm{YCbCr}$ color space omits the intensity components and use only descriptor components for skin detection which can provide robustness against changing intensity [8].

$\mathrm{YCbCr}$ is not an absolute color space rather it is way of encoding, where $\mathrm{Y}$ is luminance, $\mathrm{Cb}$ is the blue chrominance component, $\mathrm{Cr}$ is the red chrominance component and it has certain range [9].

RGB-YCbCr Equations: The basic equations to convert between 8-bit digital RGB data and $\mathrm{YCbCr}$ are

$$
\mathrm{Y}=0.299 \mathrm{R}+0.587 \mathrm{G}+0.114 \mathrm{~B}
$$




$$
\begin{aligned}
& \mathrm{Cb}=-0.172 \mathrm{R}-0.339 \mathrm{G}+0.511 \mathrm{~B}+128 \\
& \mathrm{Cr}=0.511 \mathrm{R}-0.428 \mathrm{G}-0.083+128 \\
& \mathrm{R}=\mathrm{Y}+1.371(\mathrm{Cr}-128) \\
& \mathrm{G}=\mathrm{Y}-0.698(\mathrm{Cr}-128-0.336(\mathrm{Cb}-128) \\
& \mathrm{B}=\mathrm{Y}+1.732(\mathrm{Cb}-128)
\end{aligned}
$$

If the RGB data has a range of $0-255$, as is commonly found in computer systems to avoid underflow and overflow wraparound problems, the following equations are used.

$$
\begin{aligned}
& \mathrm{Y}=0.257 \mathrm{R}+0.504 \mathrm{G}+16 \\
& \mathrm{Cb}=-0.148 \mathrm{R}-0.291 \mathrm{G}+0.439 \mathrm{~B}+128 \\
& \mathrm{Cr}=0.439 \mathrm{R}-0.368 \mathrm{G}-0.071 \mathrm{~B}+128 \\
& \mathrm{R}=1.164(\mathrm{Y}-16)+1.596(\mathrm{Cr}-128) \\
& \mathrm{G}=1.164(\mathrm{Y}-16)-0.813(\mathrm{Cr}-128)-0.391(\mathrm{~b}-128)
\end{aligned}
$$

$\mathrm{B}=1.164(\mathrm{Y}-16)+2.018(\mathrm{Cb}-128)$

\section{FEATURE EXTRACTION}

\subsection{Local Spectral Features:}

To extracting these features based on texture descriptor, with these features it is possible to describe the texture and shape of an image. it can be achieved by image can be thresholding 3x3 neighborhood pels, compared with the center feature descriptor and result used as a Local Spectral Features. It is a three valued code because center pel compared with its neighbor pels according into quantizing levels. This can be as shown below

$$
\mathrm{S}\left(n_{i}, i_{c}, \mathrm{t}\right)=\left\{\begin{array}{cl}
1 & n_{i} \geq i_{c}+t \\
0 & \left|n_{i}-i_{c}\right|<t \\
-1 & n_{i} \leq i_{c}-t
\end{array}\right.
$$

Where $n_{i}$ is the neighborhood pels, $i_{c}$ is the texture descriptor and $t$ is the applying thresholding for robust to noise because in the basic spectral feature method [10] they threshold at exactly the value of center pels, they are sensitive to the noise.

\begin{tabular}{|l|l|l|}
\hline 31 & 19 & 46 \\
\hline 27 & 25 & 72 \\
\hline 16 & 29 & 52 \\
\hline
\end{tabular}

Fig1:3X3 digital image

The $3 \times 3$ digital images as shown above fig1. The center pel consider as local descriptor and surrounding pels consider as neighborhoods. The local spectral features are obtained based on equation (13) as shown below. It contain three binary values, those are 0,1 and -1 so it is also called as three valued code.

\section{Pattem: 10101001}

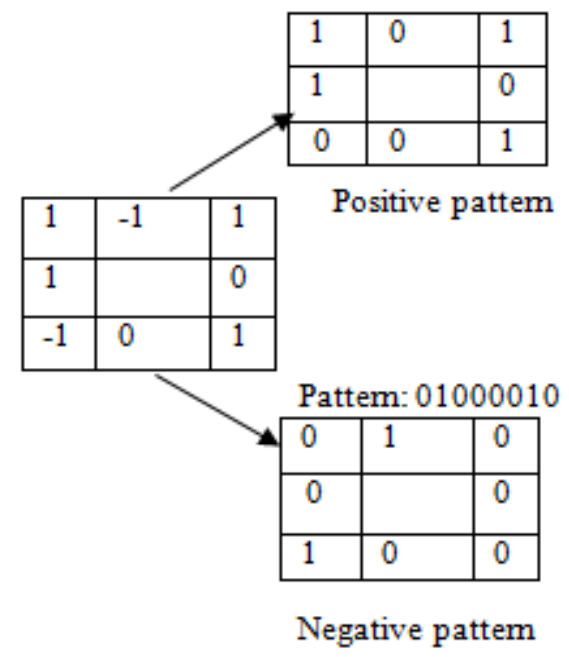

Fig2: splitting the spectral features

The above fig the spectral features split into positive spectral features and negative spectral features [11] for which separate spectrum computed, combining these results at the end of computation to form a feature vector.

The spectral feature faces of different skin colored people as shown below
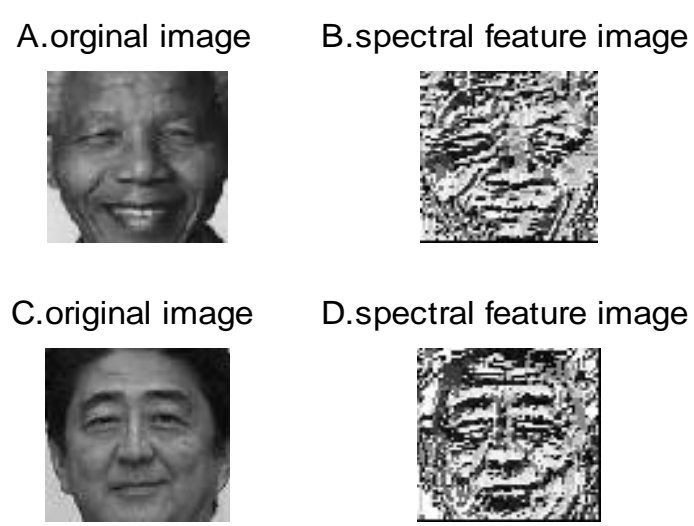

Fig3: local spectral feature images of different face skin colored people .(a)original image of black person (b) local spectral feature image.(c) original image of white person.(d)local spectral feature image.

\subsection{Gray Level Features:}

Gray level features computed from the distribution of intensities at particular positions relative to each other in image. these features depends on gray level Co-occurrence matrix[12].using this Co-occurrence matrix the gray level texture features like energy,constrast and homogeneity computed as follows. 


$$
\begin{gathered}
\text { Energy }=\sum_{i} \sum_{j} C^{2}(i, j) \\
\text { Contract }=\sum_{i} \sum_{j}(i-j)^{2} C(i, j) \\
\text { Homogeneity }=\sum_{i} \sum_{j} \frac{C(i, j)}{1+|i-j|}
\end{gathered}
$$

These three features can be computed on different skin colored people face and these features combined with colored features and spectral features to form a feature vector.

\section{FEATURE VECTOR COMPARISON}

In feature vector comparison after construction of feature vector from the query image, these feature vectors compare with the images in the database. Comparison stage takes place in two steps. In first step, we eliminate the feature vectors of the reference images which are not close enough to the feature vectors of the test image in terms of similarity. The proposed method is the Lenc-Kral Matching; it can compute the sum of the similarities between pairs of image feature vectors. For each feature vector of the test face the most similar feature vector of the gallery face is identified. The sum of the highest similarities computed and is used of similarity between two faces.

Assuming $\mathrm{Q}$ is the query image represented by $\mathrm{n}$ feature vectors $\mathrm{q}_{1}, \mathrm{q}_{2} \ldots \mathrm{q}_{\mathrm{n}}$. Let $\mathrm{D}$ be the database of $\mathrm{M}$ images and each database image consist of $m$ feature vectors $d_{1}, d_{2} \ldots . . d_{m}$ Similarity of two feature vectors $S(q, d)$ is computed by the equation shown below

$$
S\left(F_{1}, F_{2}\right)=\frac{F_{1} \cdot F_{2}}{\left\|F_{1}\right\| *\left\|F_{2}\right\|}
$$

Where $F_{1}$ and $F_{2}$ be the feature vectors of corresponding query image and database image.

For each feature vector $q_{i}$ of the query face $\mathrm{Q}$ determine by the most similar vector $d_{\max }$ of one gallery image $D_{i}$ is

$$
g_{\max }=\arg \max _{D_{i}}(s(q, d))
$$

The sum of those similarities is computed as follows:

$$
S\left(Q, D_{J}\right)=\sum_{i=1: n} g \max _{i}
$$

Where $\mathrm{n}$ is the number of query image feature vector. The recognized face is then determine by the following

$$
D^{\wedge}=\arg \max \left(D\left(Q, D_{j}\right)\right)
$$

\section{RESULTS AND DISCUSSION}

In this implementation we used 24 persons of different skin colored persons as a data base and 6 persons of different skin colored persons for query image. In this scenario used three steps for face recognition. 1 color segmentation 2.feature extraction and 3.feature vector comparison. Color segmentation used to extract the colored features from different skin colored human faces. In this example different skin colored persons can be considered. It observed that the human face is separated the skin region and non-skin region, after segmented obtained colored features like mean, standard deviation and skewness. The draw back of this color segmentation technique the components depends on only chrominance. In real world that have a chrominance in the range of human skin which may be wrongly considered as skin. To overcome this problem gray scale features are extracted.
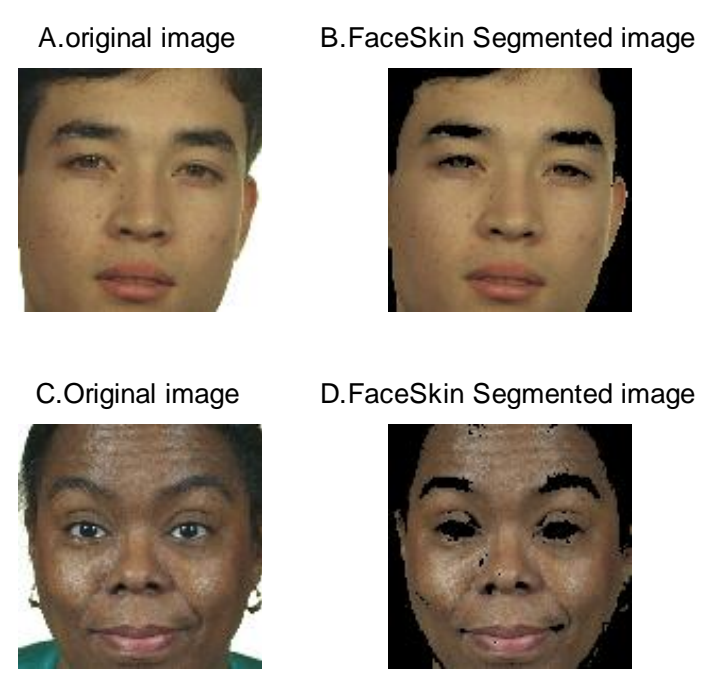

Fig4: color segmentation of different skin color people (a).white person original image (b).color segmented image. (c).black person original image (d).color segmented image

\begin{tabular}{|l|l|l|l|}
\hline $\begin{array}{l}\text { Different } \\
\text { skin colored } \\
\text { peoples }\end{array}$ & Mean & $\begin{array}{l}\text { Standard } \\
\text { deviation }\end{array}$ & Skewness \\
\hline African & $\mathbf{8 0 . 3 8 9 1}$ & $\mathbf{0 . 6 7 9 0}$ & $\mathbf{0 . 6 8 8 8}$ \\
\hline Asian & $\mathbf{7 7 . 2 2 7 9}$ & $\mathbf{1 . 9 1 6 3}$ & $\mathbf{0 . 1 3 1 4}$ \\
\hline Australian & $\mathbf{7 8 . 5 2 5 9}$ & $\mathbf{5 . 0 1 8 0}$ & $\mathbf{0 . 1 7 2 5}$ \\
\hline European & $\mathbf{1 2 8 . 2 5 6 6}$ & $\mathbf{4 . 1 6 3 2}$ & $\mathbf{0 . 7 0 7 1}$ \\
\hline $\begin{array}{l}\text { North } \\
\text { American }\end{array}$ & $\mathbf{1 0 0 . 1 0 3 5}$ & $\mathbf{3 . 3 4 3 8}$ & $\mathbf{0 . 2 8 2 9}$ \\
\hline $\begin{array}{l}\text { South } \\
\text { American }\end{array}$ & $\mathbf{7 1 . 8 3 5 5}$ & $\mathbf{2 . 9 1 9 7}$ & $\mathbf{0 . 0 9 0 7}$ \\
\hline
\end{tabular}

Fig5: colored features of different face skin colored people

The gray level features like Energy, Constract, and homogeneity of different continent people as shown below. These features can be obtained from co-occurrence matrix of an image 


\begin{tabular}{|l|l|l|l|}
\hline $\begin{array}{l}\text { Different } \\
\text { color face } \\
\text { people }\end{array}$ & Energy & Contrast & homogeneity \\
\hline African & $\mathbf{5 0 0}$ & $\mathbf{2 5 1}$ & $\mathbf{7 5}$ \\
\hline Asian & $\mathbf{5 3 3}$ & $\mathbf{3 6 0}$ & $\mathbf{7 9}$ \\
\hline Australian & $\mathbf{4 2 2}$ & $\mathbf{9 8}$ & $\mathbf{7 3}$ \\
\hline European & $\mathbf{3 7 7}$ & $\mathbf{2 6 7}$ & $\mathbf{7 1}$ \\
\hline $\begin{array}{l}\text { North } \\
\text { America }\end{array}$ & $\mathbf{5 8 4}$ & $\mathbf{1 4 3}$ & $\mathbf{8 1}$ \\
\hline $\begin{array}{l}\text { South } \\
\text { America }\end{array}$ & $\mathbf{4 2 1}$ & $\mathbf{2 4 2}$ & $\mathbf{7 0}$ \\
\hline
\end{tabular}

Fig6: Gray level features of different skin colored people

The spectral features of different face skin colored people can be obtained as shown below.it can observed that different skin colored people had a different variance and standard deviation.

\begin{tabular}{|l|l|l|}
\hline $\begin{array}{l}\text { Different face } \\
\text { color people }\end{array}$ & Variance & $\begin{array}{l}\text { Standard } \\
\text { deviation }\end{array}$ \\
\hline African & 112.5859 & 10.6106 \\
\hline Asian & 129.2323 & 11.3680 \\
\hline Australian & 156.9697 & 12.5288 \\
\hline Europe & 127.7778 & 11.3038 \\
\hline $\begin{array}{l}\text { North } \\
\text { American }\end{array}$ & 158.0202 & 12.5290 \\
\hline South American & 121.8990 & 11.0408 \\
\hline
\end{tabular}

Fig7: spectral features for different skin colored people.

The above three types of features concatenated into a single feature vector and applying Lenc-Kral Matching method for comparison of query image and correspondent gallery image.

\section{CONCLUSION}

In this work we recognized the different skin colored people using the colored features, gray level features and spectral features .These features are obtained from different skin colored persons database .combination of these features gives the more accuracy and recognized the face even different lighting conditions mainly occurred in uncontrolled environments. These three types of features form a single feature vector, applying Lenc-Kral matching method for comparison of feature vectors of database image and query image. The similarity between these two feature vectors is high then face is recognized. The applications of this type of recognition used in recognition of different continent people in airports, harbors etc.

\section{REFERENCES}

[1] AhmetBatiyar Gul,"Holistic Face Recognition by Dimension Reduction", April 2013.

[2] Nidhal k.Al abbadi, Nizar Saadi Dahir and Zaid Abd Alkareem,"Skin Texture Recognition Using Neural Networks".

[3] Nina G.Jablonski and George Chaplin, "The Evaluation of Human Skin Color Coloration", February 2000
[4] Vidut ghoshal,'Efficient face recognition system using Random forests", April 2009

[5] Turk, M.Pentland, a: Eigen face for recognition. Journal of Cognitive Neuroscience(1991)71-86

[6] Etemad, K, Chellappa, R: Discriminant analysis for recognition of human faces Images. Journal of the Optical Society of America 14(1997)1724-1773

[7] Marian stevert Batrlett,Javier R.MOvellan, and Terence J.sanowaki.Face recognition by independent component analysis,IEEE Transactions on Neural Networks, 3:1450-1452,2002

[8] Yang Ling Gu Xiaohan,"Face Detection Based on Skin Color",june 2012

[9] ITU-R BT.601-5, 1995, studio Encoding parameters of Digital Television for Standard 4:3 and wider screen 16:9 Aspect ratios.

[10] Md.AbdurRahim, Md.NajmulHossain, Tanzillah Wahid\&Md.shaflul Azam,'Face Recognition using Local Binary Patterns (LBP)", 0975-4350.

[11] Xiao yang Tan and Bill Triggs,"Enhanced Local Texture Feature Sets for Face Recognition under Difficult Lighting Conditions", IEEE Transactions on image processing, June 2010.

[12] Steven W.Zucker and Demethi Terzopoulos,"Finding structure in Co-Occurrence Matrices for Texture Analysis", computer graphics and image processing 12,286-308. 